\title{
Article
}

\section{BIM and project planning integration for on-site safety induction}

Ganah, Abdulkadir and John, Godfaurd Adjaie

Available at http://clok.uclan.ac.uk/15383/

Ganah, Abdulkadir ORCID: 0000-0002-9911-8505 and John, Godfaurd Adjaie ORCID: 0000-0002-5016-5909 (2017) BIM and project planning integration for on-site safety induction. Journal of Engineering, Design and Technology, 15

(3). pp. 341-354. ISSN 1726-0531

It is advisable to refer to the publisher's version if you intend to cite from the work. http://dx.doi.org/10.1108/JEDT-02-2016-0012

For more information about UCLan's research in this area go to

http://www.uclan.ac.uk/researchgroups/ and search for < name of research Group>.

For information about Research generally at UCLan please go to http://www.uclan.ac.uk/research/

All outputs in CLoK are protected by Intellectual Property Rights law, including Copyright law. Copyright, IPR and Moral Rights for the works on this site are retained by the individual authors and/or other copyright owners. Terms and conditions for use of this material are defined in the policies page.

\section{CLoK}

Central Lancashire online Knowledge www.clok.uclan.ac.uk

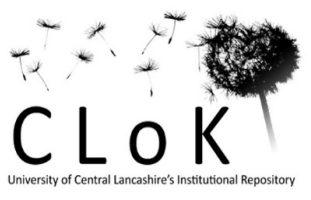




\title{
BIM and Project Planning Integration for On-site Safety Induction
}

\begin{abstract}
Purpose - The section of the research presented in this paper reviews and explores health and safety $(\mathrm{H} \& S)$ issues on construction sites. It has the sole intention of using better computer visualisation to meet the needs of site practitioners in understanding such $H \& S$ problems.
\end{abstract}

Design/methodology/approach - The methodology follows a traditional literature review approach to understand the development of BIM technology up to its current status. A questionnaire survey was conducted to gather information on the embedding of H\&S planning by site practitioners within the BIM environment.

Findings - BIM has the potential to be used in H\&S planning procedures, particularly in those related to tasks on construction sites. A framework for an integrated visual tool is developed for better H\&S practice on site. It may be used actively by all practitioners, starting with site induction, and addresses, inter alia, personal hazard perception.

Research limitations/implications - This paper provides a foundation for developing a tool that helps construction personnel explore potential H\&S risks on site before construction begins. By introducing a framework for integrating BIM and project planning, a prototype can be developed to demonstrate the application of the proposed framework.

Originality/value - The research presented in this paper introduces BIM usage during the construction stage as a tool that supports a H\&S toolbox. The paper proposes the useful framework for better $H \& S$ practice on site that can be used actively by all practitioners. The intention is to find a way forward in addressing 'real' H\&S site issues that may not be easily understood by practitioners without the full aid of visualisation scenarios.

Keywords: Health, Safety, Construction Site, BIM, 4D Modelling

\section{Introduction}

The construction sector is well known as one of the most dangerous industries in which to work (Gibb et al., 2010). Despite the fact that the UK construction sector accounts for approximately $4 \%$ of people working in the UK, $27 \%$ of all reported occupational fatalities are from the construction industry, as reported by the Health and Safety Executive, the regulatory body (HSE, 2011). The nature of the construction process contributes extensively to this relatively high fatality rate. These characteristics include the dynamic work environment, a multiplicity of operations, proximity of multiple crews, industry fragmentation and industry culture (Hallowell, 2010). Recurring problems in the construction industry led the UK government to establish a commission chaired by Sir John Egan. 
Many of the recommendations proposed by Egan in Rethinking Construction in 1998 have not been implemented by the construction industry. However, most large construction firms have made a tremendous effort to achieve the recommendation of a $20 \%$ reduction in accidents. Although there are still problems with small and mediumsize construction firms, which make up the bulk of the industry (HSE, 2011), an awareness exists among practitioners and academics of the need to find innovative solutions which will address most of the concerns Egan raised. HSE has also made progress in the areas of $\mathrm{H} \& \mathrm{~S}$ regulations, guidelines and approved codes of conduct, as well as creating H\&S awareness among construction practitioners. H\&S management is, therefore, an important consideration in all construction projects.

Although H\&S management is widely practised within all manufacturing industries, in construction site conditions cannot be controlled in terms of a 'pure' production process as we know it. As such, H\&S becomes paramount. Planning and management are prerequisites for all construction projects and their practitioners: without a deep understanding of the issues involved in construction activities, lives will be lost and extraneous costs incurred due to accidents, in addition to side effects such as the tarnished image of the firm.

Many researchers also point out that there is a lack of integration between the construction process and H\&S issues (Sulankivi et al., 2010). In order to reduce the frequency and severity of construction accidents, firms implement safety programmes and procedures that include written H\&S plans and training (Hallowell, 2010). Nevertheless, insufficient $\mathrm{H} \& \mathrm{~S}$ training and practices were identified as key factors behind many construction accidents (Sulankivi et al., 2010).

On construction sites, operatives change over time due to varying work requirements. Each construction site has its specific hazards and these differ from one location to another, which in turn cannot be generalised. New employees usually come on board without prior knowledge of the hazards they may face on a particular site. Due to their limitations, which include a lack of provision of a wider picture of the site, existing tools may not be adequate for induction training. 4D visualisation is a proven tool for demonstrating many design and construction problems, thanks to its ability to show numerous tasks in 3D over specific periods of time. This paper reports on a component of a project exploring new ways of integrating BIM technology into construction projects, in order to understand hazards and gauge its perception among inductees.

\section{Literature Review}

This section develops and discusses the literature for an integrated approach in the usage of BIM and planning software to optimise better H\&S site operations in construction projects. First, the planning literature is investigated and then the relevant literature on $\mathrm{H} \& \mathrm{~S}$ management on construction sites is explored. It also expands on the importance of construction site induction and tries to place the latter into the wider induction context, which is a must for all site personnel. This section concludes by reviewing the importance of visualisation as a critical factor in addressing some of the gaps identified within the H\&S literature. Through visualisation of hazards, it also raises the possibility of using 3D software packages to develop better ways of managing site induction. 


\subsection{Construction project planning}

Construction project planning and management is a balancing act between leading and managing people, and using and managing resources within given constraints in an efficient and effective way, in order to achieve a desired result. These constraints include, but are not limited to, time, cost, quality and safety, which are predominant during the realisation of the constructed artefact. Hence, construction project management contains both qualitative and quantitative aspects of management.

Most of what is required within the quantitative area has been codified in dedicated project management tools (i.e. planning and scheduling software), like programming in the CPM method and resource levelling. In all projects, the act of specifying, visualising and developing the planning schedule for construction has been done using dedicated work breakdown structures (WBS) within the software environment, which is now a common approach in projects. Once such plans are developed, they are then implemented to bring about the project. However, until recently, most of the information required for this planning/programming software usually came from both CAD drawings and other related sources (Watson, 2010), which are not really related in terms of WBS and subsystems used in each platform.

However, with the development of BIM, and the life cycle realisation of the project in one holistic environment, most H\&S information can be communicated directly in a single environment. There are some advantages that this paper intends to explore in relation to the use and application of the integrated approach within 4D modelling for the benefit of most site workers.

Construction site planning and operation involves the selection of temporary facilities, equipment and their operations, competent construction personnel, and the planning, organisation and selection of an effective and efficient site layout design. Construction safety induction involves familiarising personnel with site-specific $H \& S$ issues that will impinge on the progress, efficiency and productivity of personnel during site operations (John et al., 1999).

\subsection{H\&S in construction industry: site induction}

The practice of H\&S management in construction can be summarised in the following areas:

i. Safety legislation, regulation, standards and guidelines

ii. Appointment of CDM coordinator by the client

iii. Designers' H\&S considerations upstream in the creation of the artefacts and how these should be implemented during the development of the project

iv. Management of $H \& S$ management for site personnel during construction

v. Paying particular attention to the development of H\&S plans and the creation of a H\&S file through the life cycle of the project. 
Hence, $H \& S$ management is part of the wider planning and management process in a construction project. Soltani and Fernando (2004) suggested that one way to make this industry better in terms of $\mathrm{H} \& \mathrm{~S}$ is to implement effective regulations during project planning. The failure of an appropriate planning support infrastructure has adverse effects on safety, quality and productivity (Soltani \& Fernando, 2004). In a questionnaire survey to investigate the impact of adopting the H\&S provisions of Directive 92/57/EEC in 15 European Economic Community (EEC) states, Aires et al. (2010) found that $10 \mathrm{EU}$ countries had experienced a reduced workplace accident rate of more than $10 \%$, three experienced less than $10 \%$ and only two had a significantly worse rate. Some commentators also suggested that within the site organisations themselves, H\&S should be implemented, not in terms of a project-by-project basis (Ciribini \& Galimberti, 2005; Cameron \& Hare, 2008) but on a more granular level.

Construction presents significant obstacles to repeated hazard analysis. Construction sites undergo dynamic change in ways that fixed industrial facilities do not. Work teams (i.e. work gangs) are transient; thus, the physical structure and spaces change, as well as the environmental conditions (i.e. weather). Another difference is that construction workers in one team are frequently exposed to dangers created by the workers of other, unrelated teams. At any time, performing risk analysis before any activity is essential but difficult, even if the same activity is performed repeatedly, since site conditions change over time. This demands more effort than most contractors or workers are willing to invest; therefore, safety management in construction sites commonly suffers from low levels of efficiency, with effective risk analysis performed only rarely (Tang et al., 1997; Sacks et al., 2009).

In the absence of an efficient and effective way of predicting peak risk levels, safety management on construction sites is performed at a constant level of effort, focusing on provision and use of personal safety equipment, training, accident and near-miss investigations, and taking steps to fulfil regulatory requirements (Perlman et al., 2014). Given the dynamic nature of construction sites, analysis of construction activities and their related hazards is inadequate for reliable risk assessment if it does not explicitly account for the likelihood of exposure of potential victims to hazardous situations. Hence, it may be necessary to study safety hazards of sites through realistic simulated site environments.

To achieve H\&S assurance, it is necessary to have established sound codes and guides which adequately describe what good safe practice is, how it can be achieved and how it is measured. Without mention of quality assurance, this is nevertheless what is set out to be achieved in the field of temporary works (Quinion, 1991). Induction is the first point of contact both for site personnel and others who have to come on site. However, within this paper, we are limited to discussing new site personnel induction.

Most construction site personnel will tell you that although H\&S induction should be site specific, the difference from one site to another is marginal. These workers believe that they know and are familiar with the routine of site safety induction. However, as familiarity breeds contempt, personnel need reminders to make them more safety conscious, especially in terms of site hazard perceptions. One way in which this can be achieved is through visualisation. 


\subsection{Visualisation}

Most recent studies on H\&S have focused on the means by which visualisation can be used to integrate some of the problems encountered in managing by regulation and enforcement alone. Among such key commentators are those who proposed a scenario based SIMCOM+ tool to investigate safety on construction sites. It analysed structural information, including some temporary facilities, equipment, workers and materials, in order to identify on-site collisions among different entities. Using the VC_COLLIDE algorithm, Kuen-Chen et al. (2009) identified conflicts in static or dynamic construction sites and determined the distance between large dynamic objects in virtual construction sites under different scenarios. Sacks et al. (2009) proposed an algorithm based methodology CHASTE (Construction Hazard Assessment with Spatial and Temporal Exposure) that calculates the probability of a potential victim during loss of control events (Chavada \& Dawood, 2010). The following sub-sections discuss visualisation in more detail.

\subsubsection{D CAD}

A range of 3D CAD visualisation tools is used in the construction industry to communicate ideas between all stakeholders in the design and construction process of a project (Ganah et al., 2005). One of the limitations of this technique is that it does not provide a 3D representation over time, whereas $4 \mathrm{D}$ CAD does so at any specific time in the construction process.

4D modelling tools link a project's scope in 3D with the construction schedule to simulate the construction process graphically. Many research studies have discussed the potential of these tools to improve significantly design coordination and construction execution. Koo and Fischer (2000) argued that 4D models permit a review of the planned status of a project in the context of a 3D model for any desired time, which allows project managers to ensure the integrity of the main schedule, reveal potential time-space conflicts and logistical problems, support the communication of product and process knowledge, and enable efficient tracking of work progress. Furthermore, 4D models facilitate communication with subcontractors and improve collaboration between the project team.

As part of the process of understanding site hazards before going on site, the use of 4D models may also help in identifying and eliminating many construction related problems (Aouad \& Tanyer, 2005). These models display the progression of construction over time and sometimes dramatically improve the quality of construction plans and schedules (Rischmoller et al., 2001).

4D CAD proved itself a useful tool in assisting planners to visualise alternative construction sequences based on various decisions made (Koo \& Fischer, 2000; Dawood et al., 2001). However, it should not be considered as the only planning tool, as it relies on available information to provide a graphical simulation of the project schedule. The planner then uses these tools as a means of visualising and comparing, rather than developing and implementing, different decision alternatives (Waly, 2001).

Traditional approaches used for representing planning information in an abstract textual description of construction activities may lead to planners requiring a visual conceptualisation of the sequence of construction activities, while subcontractors may 
need to elaborate on the construction plan because it lacks necessary detail (Rwamamara et al., 2010). These omissions can be provided through graphical visualisation methodology, for example Building Information Modelling (BIM).

\subsubsection{BIM}

BIM - also known as Object-orientated Modelling Technology - was originally used in architectural design. However, it has become more widespread in structural and services engineering. The term BIM does not merely refer to a category of leading-edge software for designing buildings but goes beyond that to a process view in which the focus is on information over the full life cycle of a building (Watson, 2010). It relates directly to a project team's ability to visualise, understand, communicate and collaborate. Harty et al. (2010) considered BIM as a set of practices or activities describing new ways of working that emerged through the implementation process. Succar (2009) gave a deeper insight into BIM, defining it as a set of interacting polices, processes and technologies generating a methodology to manage key building design information in a digital format throughout the building life cycle.

Nowadays, each construction project is a complex and dynamic system that makes construction planning and design, and site and construction management complex and difficult (Zhang \& Li, 2010). BIM is widely considered an enabling technology with the potential to boost communication between stakeholders, enhance the quality of information available for decision making and improve the quality of services delivered, thus reducing time and cost at every stage in the life cycle of a building (Smith \& Tardif, 2009). One of the key advantages of IBM over 2D and 3D CAD is that it represents and manages not just graphics but also information - information that allows the automatic generation of drawings and reports, design analysis, scheduling simulation and facilities' management, ultimately enabling the building team to make better-informed decisions. The planned sequence of work is usually part of BIM, which can be used later to produce animations of the construction process over time, thereby showing how the work on site should be carried out according to plans of work and contractual responsibilities. Moreover, BIM has the potential to be used beyond the design stage and include the construction and operation of a building through the concept of a digital virtual building that parallels the real one (Watson, 2010). Thus, the technology can prove crucial to the success of a project by effectively controlling the construction schedule, budget and quality, and by reducing risks (KU \& Mills, 2010) through time-controlled realistic simulation.

BIM technology has the potential to be used in safety planning procedures, particularly those related to tasks on construction sites. 4D modelling tools can be used to link a project's scope in 3D with the construction schedule and graphically simulate the construction process. Construction tasks on site can be modelled in a 4D CAD production model, in which the model produced by designer becomes the starting point. Previous studies have found that certain sets of movement characterise construction facilities like tower crane arm motion and that of construction vehicles. This may enable a system to simulate construction more realistically (Zhang \& Li, 2010).

Harty et al. (2010) investigated the use of BIM to assess the adequacy of access for installing new services and performing $H \& S$ assessment - looking for trip hazards. This 
project did not investigate how on-site $H \& S$ during construction can be assessed and addressed. The utilisation of 4D-BIM technology may improve occupational safety by connecting safety issues more closely. However, the uptake of this technology within the construction industry is partial and fragmented (Harty et al., 2010).

This literature review shows that, as of now, BIM usage is confined mostly to the design and planning stages of a project, with very little of it relating to $H \& S$ through hazard perception being used during construction. However, the latter is where the bulk of accidents and $H \& S$ occurrences are recorded. Also, that is the phase when induction is ongoing due to the high churn rate of personnel in the construction industry. A concentration of contracting firms (i.e. medium and small firms and subcontractors) is predominant within the construction phase. However, software planning packages are not frequently used by these subcontractors to keep track of progress, as few of these subcontracting firms actively practise tracking their projects through computerised planning tools. New methods are needed to help alleviate some of these problems that may be contributing factors in proactively appreciating $\mathrm{H} \& \mathrm{~S}$ management.

\section{$3 \quad$ Research Methodology}

The focus of the paper is on the use of BIM H\&S for construction site induction. The methodology is more qualitative than quantitative in approach. As such, the first stage of the project is to assimilate all the relevant literature in understanding our study domain. A traditional method of literature review was followed in which authentic and credible resource materials were investigated. This embraces literature on BIM, visualisation, planning, health, safety and risk in construction projects, as well as other associated works. The research instrument chosen is an eclectic approach to the literature which involves both deductive and inductive understanding for future syntheses of the knowledge gained.

The search used within the literature review process is that all documents are dated no earlier than 2002 and contain the term BIM. It became popular after the release of a white paper by Autodesk Building Design Solutions describing building information modelling and discussing its benefits to the construction industry (Autodesk, 2002). This review, in effect, follows the trend of BIM progress from this point onwards. The sources used in this study come from the following, in order of relative importance to academic rigour: Science Direct, Emeralds Engineering, Sage, ARCOM COBRA, CIB W078 and CIB W099. A keyword search technique was employed to find information relevant to the adoption of BIM for $H \& S$ communication in construction, using the terms BIM, H\&S, communication, site induction and construction. The data gathered was then categorised as key information and supportive information based on its relevance to the research study and how it could be used.

From the knowledge gained from the literature, a questionnaire survey was developed with the two themes of BIM and H\&S communication on site. All questions were measured through a Likert-type response format. Properties relating to each of the survey questions were used in the form of statements to measure participants' understanding of the topic under investigation. Participants were asked to endorse the statements using a five-point Likert scale from 1 "strongly disagree" to 5 "strongly agree". 
After the draft questionnaire had been developed, it was given to five practitioners to check its, content validity, before being distributed to the chosen sample. A random sampling strategy was adopted for the top 1,000 practitioners based on their annual turnover. Two hundred construction practitioners were randomly selected from these UK companies. A total of 46 questionnaires were returned and analysed, representing a response rate of $23 \%$, which is an acceptable return for a questionnaire survey (Malhotra \& Grover, 1998).

To reach a required level of data reliability, the questionnaire achieved its objective of reaching those who were closely involved in delivering construction projects (Oppenheim, 1992; Naoum, 2012). Posting it to organisations in different regions of the UK minimised the duplication of selected projects. All 46 respondents provided their business details, which revealed that all hold senior positions within their companies and have influence in the management of $H \& S$.

\section{Results and Discussion}

This section is divided into two main parts. The first is concerned with the essential elements of communication for achieving better $\mathrm{H} \& \mathrm{~S}$ on site with visualisation enhancement, while the second is about developing the integrated framework that will enhance better H\&S knowledge and understanding with respect to construction site induction.

\subsection{On-site H\&S communication issues}

There are several theories of communication (Shannon \& Weaver, 1948; West \& Turner, 2010; Wood, 2004; Windahl et al., 2009). This paper adopts a perspective regarding these theories that aligns itself with the practices of the construction industry. Communication includes both the medium employed and the core knowledge, which form the basis for mutual understanding of team participants.

Bennet (1985) stated that there are two categories of interaction which match the basic characteristics of teams. The first is concerned with the communication of information. The latter should first be translated into text or graphics that the other team is likely to understand. These texts or graphics need to be communicated to the other team through an appropriate medium (Ganah et al., 2000). The second category of interaction is that concerned with clear work organisation which allows the activities of teams to fit together. In other words, teams should coordinate their actions.

Methods of $H \& S$ Communication: In this industry, site teams and other participants in construction projects communicate using traditional methods, such as face-to-face meetings, paper-based drawings, schedules and written statements. The construction industry displays some inertia in adopting new technology to change its methods of communicating and innovating. The use of telecommunication systems like facsimile, email and mobile phones has improved communication in respect of speed but has not influenced the efficiency of the process or the quality of information exchanged (Alshawi \& Underwood, 1999), especially with respect to H\&S of all workers on site. 
In recent times, there have been great leaps made in technology for on-site communication, with the introduction of wireless internet, personal digital assistant (PDA) systems, IP communications and CAD, as well as BIM technology and innovations. Knowledge of such new technologies is prevalent within the industry but tends to concentrate in its upstream end, that is, the design and consultancy area, as well as in educational institutions. This knowledge needs to be translated to the downstream end of the industry, namely, on-site activities through subcontractors. The core knowledge to be communicated within the different participants is known but needs to be translated into a new medium for communicating in an effective and efficient manner.

Communication Management: Management is expected to use a variety of formal and informal means to promote and communicate its commitment to safety (Baxendale \& Jones, 2000). Simon and Piquard (as cited in Mohamed (2002)) claim that both management communication and employee feedback are critical for safety improvements and reporting near misses and unsafe conditions and practices. Most current H\&S communication on construction sites tends to be one-directional without feedback from the operatives or any recording of their carrying out various activities.

On Site $H \& S$ Communication: From the information garnered in the literature review, a questionnaire was developed and sent to practitioners to ascertain current on-site communication methods. The analysis of this survey is reported in the ensuing paragraphs.

From the analysis of results as presented in Table 1, expressed as percentages of practitioners' responses, it appears that toolbox meetings, followed by workshops/seminars and HSE guides, are regarded as the current best forms of communication to site operatives. Currently, on-site communication using BIM and other visualisation tools is not a common practice. It may appear that BIM is not so well known and, therefore, scores lowest. The reasons for this may be that contractors on site are not yet familiar with the BIM technology and the innovation and value-added possibilities it will bring. Secondly, fragmentation among practitioners does not lend itself to effective and efficient communication pathways. Practitioners from different disciplines are not comfortable with sharing their knowledge of this new innovation. Therefore, the diffusion of the technology is slow to be assimilated by those downstream, that is, the subcontractors in the construction process.

Although meetings (i.e. toolbox meetings) are recorded, they are not captured in visualisation format, such as feedback in other forms of communication (i.e. body language) which can be reported back to site operatives. Also, some aspects of communication that require visualisation mainly revert to $2 \mathrm{D}$ methods of communication, which does not bring out successfully the safety elements required, especially in variation order. 


\begin{tabular}{|c|c|c|c|c|c|c|c|c|c|}
\hline Method & 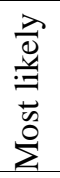 & 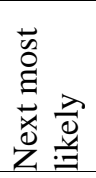 & 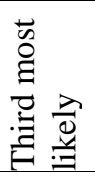 & 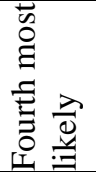 & 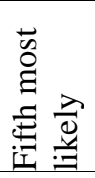 & 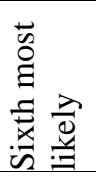 & 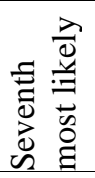 & 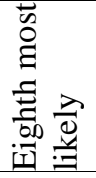 & 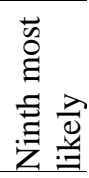 \\
\hline A) Safety toolbox meetings & 77 & 12 & - & 9 & - & - & - & - & 2 \\
\hline B) HSE Guides & 2 & 28 & 19 & 18 & 21 & 7 & 5 & - & - \\
\hline $\begin{array}{l}\text { C) Building Information Modelling } \\
\text { (BIM) }\end{array}$ & - & 2 & 2 & 10 & 9 & 5 & 17 & 17 & 38 \\
\hline D) E-Learning & - & - & 5 & - & 12 & 20 & 29 & 27 & 7 \\
\hline E) Simulation onsite. & 5 & 17 & 38 & 5 & 9 & 5 & 9 & 7 & 5 \\
\hline F) Workshops/Seminars & 17 & 31 & 19 & 24 & 2 & 3 & - & 2 & 2 \\
\hline G) DVD & 7 & 20 & 12 & 15 & 22 & 12 & 5 & 5 & 2 \\
\hline H) Downloaded Files & - & 5 & 7 & 19 & 19 & 26 & 5 & 12 & 7 \\
\hline I) Distance Learning & - & - & 2 & 2 & 7 & 14 & 23 & 23 & 28 \\
\hline
\end{tabular}

A key question asked was:

'To what extent do you think that it would be feasible for a single guide, such as in " $H \& S^{\prime}$, to adequately cover the main H\&S issues on the construction site?'

From Table 2 below, we can see that $66 \%$ of practitioners favour the introduction of a single H\&S guide that would be used on site; some of the respondents commented that the guide would even be better if it could incorporate visualisation in the way it is presented. However, $27 \%$ think that this is probably not feasible, which represents quite a substantial number. We should not forget that H\&S itself is self-regulated through a single organisation, HSE. Since its inception, the latter has consistently been driving down construction accidents significantly. It is, therefore, feasible that a single guide or point of entry will augment the way $H \& S$ is practised on site, if fully controlled by the regulating body. This is where BIM technology comes into play.

Table 2: Respondents' view on a single H\&S guide

\begin{tabular}{ll}
\hline Response & Percentage \\
\hline Very feasible & 31.8 \\
Feasible & 34.2 \\
Unsure & 6.8 \\
Probably not feasible & 22.7 \\
Definitely not feasible & 4.5 \\
Total & 100.0 \\
\hline
\end{tabular}

From the evaluation of the questionnaire survey on construction site communication, it appears that practitioners appreciate a holistic environment in which $\mathrm{H} \& \mathrm{~S}$ can be communicated to employees, as well as to all levels of practitioners on site. One way through which this can be achieved is by developing an integrated environment that will contain all relevant persistent data required for not only on-site induction but also for daily issues that relate to the dynamic environment. This environment will also use some of the existing methods in augmenting the way that issues are managed; the only 
difference is that it is in a single environment. This development is the integrated BIM and safety induction platform.

The next stage used the knowledge gained from the analysis to develop a generic modelling approach that takes into consideration the object-orientated modelling understanding used in both BIM technology and planning software. This incorporated developing new classes, frameworks and building blocks that replicate the use of the integrated scenario for each construction site. However, for this paper, a section of the different stages is reported to give the reader an understanding of how the research developed.

\subsection{Integrated BIM approach to site induction}

Rather than expose the individual to 'real' H\&S concerns, the specific site accident 'hot spot' can be simulated and the improvement to workers' hazard perception improved considerably, with the aid of BIM and project management software in sync (i.e. 4D modelling). In Figure 1, the architecture is presented.

The architecture of the site induction hazard perception toolkit is made up of four parts:

- The BIM software with its library of information

- The project management software with the resources and planning of the desired project

- The algorithms making use of information from both packages

- The user interface

Before integration can commence, the planning software and the BIM should have a means of integrating the information of a particular object that is to be created, such that recognition of such object is seamless in any environment. Secondly, the different stages of the object in real time should be stored in such a way that a time sequence scenario can be created in the BIM environment. Thirdly, the visualisation of the developing project should be such that safety concerns can be visualised as the project progresses. 


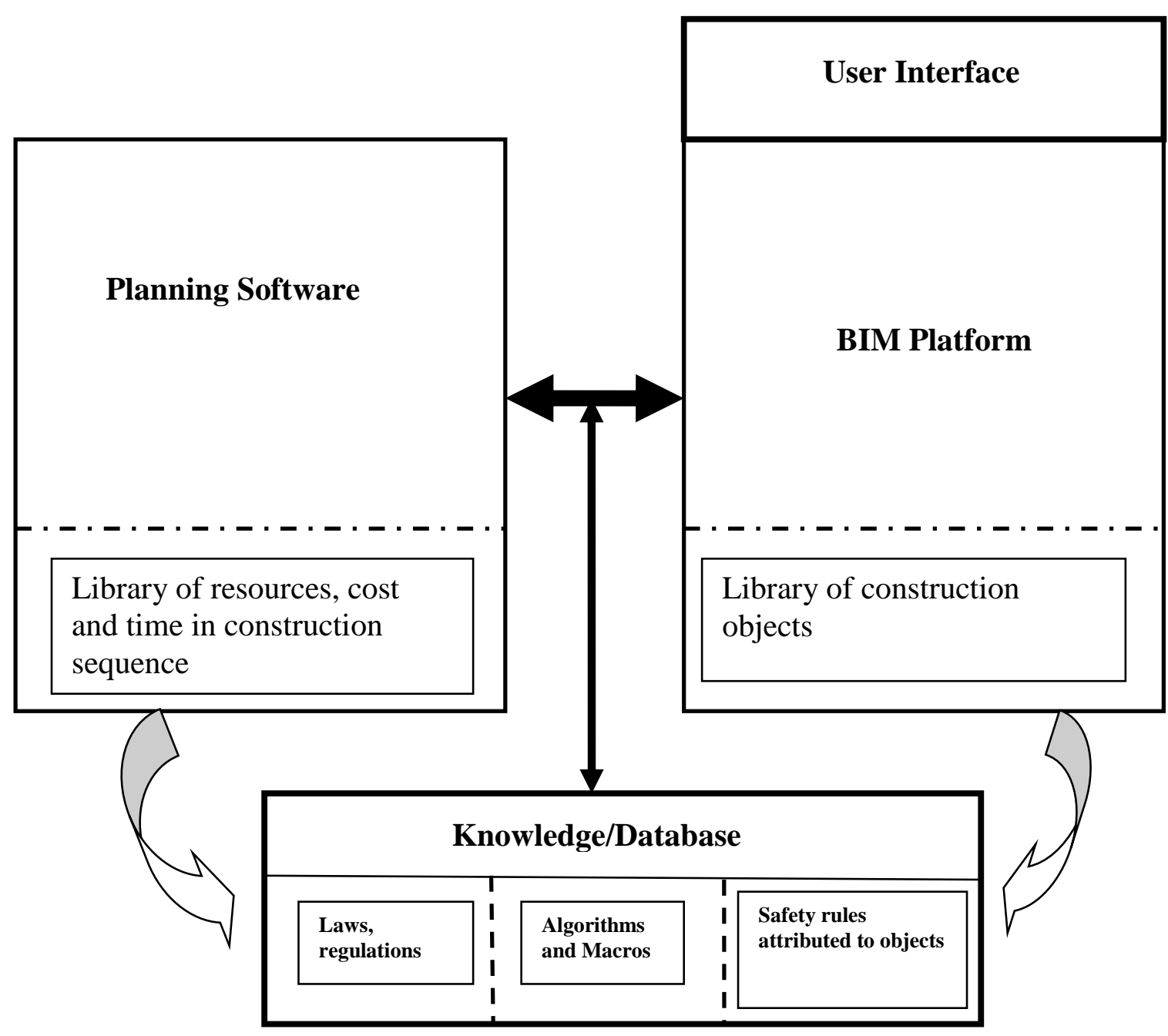

Figure 1: Top Level Site Safety Induction Framework

As the construction sequence is developed, the integration should be able to monitor critical safety areas and show in time sequence how certain hazards develop on site, through the expert system that lies behind the 4D scenario.

Each part of this architecture is being developed using an object-orientated methodology and SSM. Therefore, each part is considered a high-level object in its own right and will be developed independently.

The BIM environment will be used to develop the 'new' construction components that will be directly related to the WBS used within the scheduling software. Critical safety areas will be developed to show the site inductee what he should be expecting on site.

Algorithms will be used to control the different construction scenarios that will typify site perceptions in a realistic environment. New recruit hazard awareness will be tested in the past completed stages of the project, ongoing work and future realistic phases of the project. This will all be made possible by algorithms augmenting the H\&S regulations, codes and guidelines at each stage of the project. 


\section{Conclusion}

If not properly managed, $\mathrm{H} \& \mathrm{~S}$ on a construction site can either make or break a contractor. Hence, all personnel need to be properly inducted in managing their $H \& S$ concerns, which is usually done by current site induction methods.

Construction personnel are always inducted when they are new to a specific site, through a prescribed induction manual and training that have been developed by industrial institutions or as in-house induction material. Over time, personnel moving from one site to another become familiar with the induction material and take the process for granted. However, accidents are still occurring on sites and, hence, more proactive methods are required. BIM is now prevalent within the construction industry, especially in design and planning of construction projects. Usage of BIM in this research on construction execution has the potential to help augment practitioner understanding of their sites and, by so doing, reduce the probability of accidents through better visualisation and a planned BIM-augmented approach. The Building Information Construction Health and Safety (BICHS) project tried to develop a new way of enhancing worker understanding of site hazards, especially in real time, as site induction can happen as a project progresses.

\section{Future Research Work}

The development of intelligent algorithms for identifying site hazards will be the next stage of this research project. These systems will enable new construction site operatives to identify, as part of their H\&S induction training, potential hazards they may face in their work. They will be tested and validated through real-life case studies and measurement matrices developed as a way of gauging hazard perception on the part of people on site.

\section{References}

Aires, D.M., Gamez, C.R. \& Gibb, A., 2010. Prevention Through Design: The effect of European Directives on Construction Workplace Accidents. Safety Science, 48(2), pp.248-58.

Alshawi, M. \& Underwood, J., 1999. The Application of Information Techn. London: RICS.

Aouad, G. \& Tanyer, A., 2005. Moving beyond the fourth dimension with an IFC-based single project database. Automation in Construction, 14(1), pp.15-32.

Baxendale, T. \& Jones, O., 2000. Construction design and construction management safety regulations in practice - Progress and implementation. International Journal of Project Management, 18(1), pp.33-40.

Bennet, J., 1985. Construction Project Management. London: Butterworths. Cameron, I. \& Hare, B., 2008. Planning tools for integrating health and safety in construction. Construction Management and Economics, 26(9), pp.899-909.

Chavada, R. \& Dawood, N., 2010. An innovation approach to integrate H7S issues in the construction project planning using serious game engine technologies. In Kkanae, K., Yabuki, N. \& Kashiyama, K., eds. Poroceedings of the 10th Innternational conference on construction applications of virtual reality. Sendari, Japan, 2010. 
Ciribini, A. \& Galimberti, 2005. 4D project planning and H\&S management. [Online] Available at: http://itc.scix.net/cgi-bin/works/Show? id=w78-2005-d3-3ciribini\&sort=DEFAULT\&search $=\% 2$ fseries $\% 3 \mathrm{a} \% 22 \mathrm{w} 78 \% 3 \mathrm{a} 2005 \% 22 \&$ hits $=101$. Dawood, N., Spiprasert, E., Mallasi, Z. \& Hobbs, B., 2001. Development of an integrated infomration resources base for $4 \mathrm{D} / \mathrm{VR}$ construction processes simulation. In AVRII and CONVR2001. Chalmers, Gothnburg, Sweden, 2001.

Ganah, A., Anumba, C.J. \& Bouchlaghem, N.M., 2000. The use of visualization to communicate design information to construction sites. In Proceedings of 16th Annual ARCOM Conference. Glasgow, UK, 2000.

Ganah, A., Bouchlaghem, N., J. \& C., A., 2005. VISCON: Computer visualisation support for Constructability. ITCon, 10, pp.69-84.

Gibb, A.G., Brace, C.L., Pendlebury, M. \& Bust, P.D., 2010. How can we prevent construction accidents? Outcomes from a stakeholder consultation: project and workplace influences. In Proceedings of the 18th CIB World Building Congress. Salford, UK, 2010. CIB Publucation 357.

Hallowell, M., 2010. Cost-effectiveness of construction safety programme elements. Construction Management and Economics, 28(1), pp.24-34.

Harty, C., Throssell, D., Jeffrey, H. \& Stagg, M., 2010. Implementing building information modelling: a case study of the Barts and the London hospitals. In Proceedings of the International Conference on Computing in Civil and Building Engineering, ICCBE. Nottingham, UK, 2010.

HSE, 2011. Construction accidents intelligence. Report prepared by the Health and Safety Excutive.

John, G.A., Anumba, C.J. \& Hobbs, B., 1999. Towards a virtual environment for safetyintegrated site layout design and organization. In Proceedings of 2 nd International Conference of CIB Working Commission W99. Honolulu/ Hawaii/ 24-27 March 1999, 1999.

Koo, B. \& Fischer, M., 2000. Feasibility study of 4D CAD in commercial construction. Journal of Construction Engineering and Management, 126(4), pp.251-60.

Kuan-Chen, L. \& Shih-Chung, K., 2009. Collision detection strategies for virtual construction simulation. Automation in Construction , 18(6), pp.724-36.

KU, K. \& Mills, T., 2010. Research needs for building information modelling for construction safety. In International Proceedings of Associated Schools of Construction 45th Annual Conference. Boston, MA, 2010.

Malhotra, M.K. \& Grover, V., 1998. An assessment of survey research in POM: from constructs to theory. Journal of Operations Management, 16(4), pp.407-25.

Mohamed, S., 2002. Safety climate in construction site environments. Journal of Construction Engineering and Management, 128(5), pp.375-84.

Naoum, S.G., 2012. Dissertation research and writing for construction students.

Routledge.

Oppenheim, A.N., 1992. Questionnaire Design, Interviewing and Attitude

Measurement. London: Continuum.

Perlman, A., Sacks, R. \& Barak, R., 2014. Hazard Recognition and Risk Perception in Construction. Safety Science, 64(April), pp.22-31.

Quinion, D.W., 1991. The benefits of UK guidance for temporary works. In

Proceedings of Construction Congress '91,. CAMBRIDGE, MASSACHUSETTS,

APRIL 13-16, 1991, 1991. 
Rischmoller, L., Fisher, M., Fox, R. \& Alarcon, L., 2001. 4D planning and scheduling (4D-PS): grounding construction IT research in industry practice. In Proceedings of the Construction Information Technology CIB W78 International Conference-IT in Construction in Africa. Mpumalanga, South Africa, 2001.

Rwamamara, R., Norberg, H., Olofsson, T. \& Lagerqvist, O., 2010. Using visualization technologies for design and planning of health construction workplace. Construction Innovation: Information, Process, Management, 10(3), pp.248-66.

Sacks, R., Rozenfield, O. \& Rosenfield, Y., 2009. Spatial and temporal exposure to safety hazards in construction. Journal of Construction Engineering and Management, pp.726-36.

Shannon, C.E. \& Weaver, W., 1948. A mathematical theory of communication. Bell Laboratory.

Smith, D.K. \& Tardif, M., 2009. Building Information Modelling: A Strategic Implementation Guide for Architects, Engineers, Constructors, and Real Estate Asset Managers. Hobiken, NJ: John Wiley \& Sons, Inc.

Soltani, A.R. \& Fernando, T., 2004. A fuzzy based multi-objective path planning of construction sites. Automation in Construction, 13(6), pp.717-34.

Succar, B., 2009. Building information modelling framework: A research and delivery foundation for industry stakeholders. Automation in Construction, 18(3), pp.357-75.

Sulankivi, K., Kahkonen, K., Makela, T. \& M, K., 2010. 4D-BIM for construction safety planning. In W099-Special Track 18th CIB World Building Congress 10th-13th May 2010. Salford, UK, 2010.

Tang, S.L., Lee, H.K. \& Wong, K., 1997. Safety cost optimization of building projects in Hong Kong. Construction Management and Economic, 15(2), pp.177-86.

Waly, A.F., 2001. Virtual Construction Environment (VCE) for Macro Planning. Watson, A., 2010. BIM- a driver for change. In Proceedings of the International conference on Computing in Civil and Building Engineering, ICCBE 2010. Nottingham, UK, 2010. Nottingham University Press.

West, R. \& Turner, L., 2010. Understanding interpersonal communication: Making choices in changing time. Boston, USA: Wadsworth Cengage Learning.

Windahl, S., Signitzer, B. \& Olson, J., 2009. Using Communication Theory: An Introduction to Planned Communication. SAGE Publications Ltd.

Wood, J.T., 2004. Communication Theories in Action: An Introduction. Cengage Learning.

Zhang, J. \& Li, D., 2010. Research on 4D virtual construction and dynamic management system based on BIM. In Proceedings of the International Conference on Computing in Civil and Building Engineering, ICCBE 2010. Nottingham, UK, 2010. Nottingham University Press. 